\title{
Aiguillage d'une protéine vers la mitochondrie
}

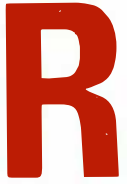
esponsables de la respiration cellulaire, les mitochondries existent dans toutes les cellules de l'organisme, bien qu'en quantités très variables. En dehors du noyau, elles sont seules à posséder un ADN propre mais celui-ci ne code que pour une vingtaine de protéines (voir Lexique de médecine) sciences $\mathrm{n}^{\circ} 5$, vol. 1, p. 276) et la très grande majorité des quelques 200 protéines qu'elles contiennent sont codées par des gènes du noyau. Partageant avec d'autres la nécessité de sortir du cytoplasme, ces protéines sont en outre synthétisées sur les ribosomes libres et non sur ceux liés aux membranes. Quels facteurs aiguillent ces protéines vers la mitochondrie, puis leur dictent soit de s'arrêter sur leur membrane extérieure, soit de se transporter à l'intérieur?

Premier indice : le précurseur, ou "guide": la protéine (ou sa sousunité) est synthétisée sous forme d'un précurseur dont la portion $\mathbf{N}$ terminale va la diriger dans la bonne direction. Appelée peptide signal, puis séquence "guide" (leader), celle-ci compte le plus souvent 25 à 30 acides aminés qui seront éliminés après l'entrée dans la mitochondrie. Il est relativement facile d'en faire l'analyse, puisqu'on peut cloner la protéine et analyser l'ADN de ces séquences. Aucune homologie entre elles, mais des analogies : elles sont riches en acides aminés basiques, en sérine et thréonine, pauvres en acides aminés acides; la charge de cette séquence guide est donc basique. $\mathrm{Si}$ l'on incube des mitochondries isolées avec le précurseur, celui-ci est capté puis clivé; la même expérience effectuée avec la protéine mature reste négative.
Mais deux questions se posent alors : assurément nécessaire la séquence-guide est-elle suffisante? en outre, quelles modifications abolissent ses propriétés? Deux groupes ont abordé le problème sur deux types de matériel très différents mais avec une méthode similaire. Elle consiste à lier la séquence signal d'une protéine mitochondriale à une protéine qui normalement reste dans le cytoplasme : la dihydrofolate réductase (DHFR). La première question a été résolue sans ambiguité par Horvich et al. à Yale [1]. Ils ont fusionne l'ADN de la séquence-guide de l'ornithine transcarbamylase humaine (OCT) avec celui de la DHFR et ont fait exprimer le produit dans des cellules $\mathrm{CHO}$ qui normalement ne font pas de DHFR. Par des méthodes immunologiques, ils ont montré la présence d'un précurseur chimérique de $26 \mathrm{KD}$ et de DHFR clivée de $20 \mathrm{KD}$ dans les mitochondries. Le groupe suisse de Schatz [2] a obtenu des résultats analogues en fusionnant l'ADN de la séquenceguide de 25 acides aminés d'une sous-unité de la cytochrome $c$ oxydase de levure à celui de DHFR, l'ensemble s'insérant dans des mitochondries de levure.

La deuxième question, relative aux modifications, soulève d'immenses difficultés. L'abord du groupe américain a consisté à remplacer les acides aminés basiques de la séquence-guide par des acides aminés neutres : reconnaissance et captation disparaissent. Les auteurs suisses sont allés plus loin, raccourcissant progressivement la préséquence fusionnée à la DHFR. Il suffit en effet des 12 premiers acides aminés de la préséquence pour conduire d'une main sûre une pro- téine à la mitochondrie. A noter toutefois que dans ces conditions, le clivage entre préséquence et DHFR ne s'effectue plus.

Les deux exemples que nous venons de donner montrent à la fois les progrès dans le domaine complexe de l'aiguillage des protéines vers leur destination et les limites actuelles de ces progrès.

Ces recherches pourraient avoir des prolongements importants en pathologie. Le déficit en OCT est une maladie récessive liée au sexe et d'une hautre gravité. A côté des deux mécanismes classiques invoqués pour l'expliquer : absence de synthèse ou fabrication d'une enzyme défectueuse (inactive ou instable), une troisième possibilité est maintenant à explorer, celle d'une OCT qui s'arrêterait en route et n'atteindrait pas la mitochondrie. Riche d'avenir, cette hypothèse pourrait s'appliquer à toutes les maladies des mitochondries - on en connait plusieurs dizaines mais aussi à celles d'autres organites subcellulaires. Rappelons que nous avons donné dans $m / s, \mathrm{n}^{\circ} 7$, p. 392, un exemple de ces protéines " embourbées" dans le déficit en sucrase-isomaltase de la muqueuse intestinale.

$$
\text { J. C.-D. }
$$

Horwich AL, Kalousek F, Mellman I, Rosenberg LE. A leader peptide is sufficient to direct mitochondrial import of a chimeric protein. Embo 7 1985; 4 1129-35.

Hurt EC, Pesold-Hurt B, Suda K, Oppliger W, Schatz G. The first twelve aminoacids (less than half of the presequence) of an imported mitochondrial protein can direct mousc cytosolic dihydrofolate reductase into the yeast mitochondrial matrix. Embo f 1985; 4 : 2061-8.

Kolata G. How do proteins find mitochondria ?
Science 1985; $228: 1517-8$.
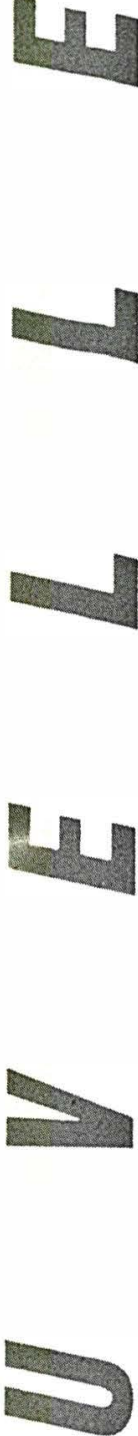

$\mathrm{m} / \mathrm{s} n^{0} 8$ décembre 85
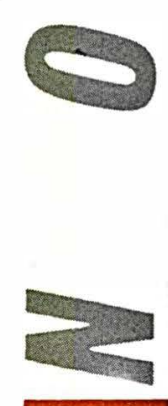